www.jmscr.igmpublication.org

Impact Factor 5.84

Index Copernicus Value: 71.58

ISSN (e)-2347-176x ISSN (p) 2455-0450

crossref DOI: _https://dx.doi.org/10.18535/jmscr/v5i11.62

Journal Of Medical Science And Clinical Research

\title{
Analysis of Functional Outcome of Bioabsorbable Screws in Arthroscopic Assisted Anterior Cruciate Ligament Reconstrution
}

\author{
Authors \\ S.Sankar $^{1}$, A.Manikandarajan ${ }^{2}$, P.S.Balamurugavel ${ }^{3}$, Dhanpal Singh ${ }^{4}$, \\ R.Neelakrishnan ${ }^{5}$ \\ ${ }^{* 1}$ Postgraduate in Orthopaedics, RMMCH, Annamalai University \\ ${ }^{2}$ Lectutre, Department of Orthopaedics, RMMCH, Annamalai University \\ ${ }^{3}$ lecturer, Department of Orthopaedics, RMMCH, Annamalai University \\ ${ }^{4}$ Professor of orthopaedics, RMMCH, Annamalai University \\ ${ }^{5}$ Professor \& Head of Department, Orthopaedics, RMMCH, Annamalai University
}

Abstract

Aim: Prospective analysis of functional final results of bioabsorbable screws in arthroscopic assisted anterior cruciate ligament reconstruction.

Materials \& Methods: A prospective study done at the Department of Orthopaedics, Rajah Muthiah Medical College \& Hospital, Annamalai University, Chidambaram. All instances of anterior cruciate ligament tear with in age group of 18 to 45 years have been taken up for surgical procedure and Follow up completed at everyday intervals for a length of 2 years.

Results: 40 patients with ACL tear have been handled with bioabsorbable screws from June 2015 to June 2017. Mean age of the patients 30.7 years (18-45 years).The mean IKDC rating is 94.33 .

Conclusion: In our observe, Patients with ACL reconstruction with bioabsorbable screws had consequences that have been similar with that of other research finished elsewhere with correct functional final results.

Keywords: Anterior cruciate ligament tear, Bioabsorbable screws.

\section{Introduction}

Anterior cruciate ligament repair remains one of the maximum common orthopaedic tactics, in particular related to sports participation at any stage $^{[1]}$. Several strategies are in modern-day use with achievement success rate between $65 \%^{[2]}$ and $95 \%{ }^{[3]}$. Over several years, fixation for ACL reconstruction has been done with metallic interference screws ${ }^{[4]}$. Metallic screws proved to attain strong preliminary fixation and to provide osseous integration in grafts with bony components $^{[5]}$. However, numerous worries have arisen due to its application in soft tissue grafts ${ }^{[6]}$, for instance, due to the danger of graft harm or of offering more fragile reconstructions. Furthermore, the use of metallic devices creats some distrubances in MRI assessment [7], and some calls for implant elimination for the duration of ACL revision surgery, accordingly enforcing elevated problem in an always traumatic process. $^{[5,11]}$

For a majority of these motives, and with tendencies inside the bioengineering and biomaterials fields, it's been said that the correct implant need to be biocompatible, biomimetic, and biodegradable ${ }^{[8]}$, even as warranting robust 
preliminary fixation with minimum graft damage ${ }^{[39]}$.

A latest level II meta-evaluation from Emond et al. ${ }^{[5]}$ has shown that there aren't any substantial differences in surgical outcomes related to bioabsorbable screws as evaluate with titanium screws for ACL reconstruction. Previously, Shenetal ${ }^{[9]}$, additionally in a meta-analysis of 10 randomized controlled trials comprising 790 patients, determined no surgical outcome distinction between two groups, however observed a higher occurrence of knee effusion with bioabsorbable screws. However, restricted information is supplied about the biologic characterization of such implants and on feasible overseas body reactions.

Concerns associated with the use of bioabsorbable interference screws encompass intraoperative screw breakage, inflammatory reaction main to accelerated or incomplete absorption, joint effusion, encapsulation, screw migration with similarly harm (articular or not), expanded price, and the capability for bone tunnel widening.

\section{Aim of Study}

The aim is prospective study of the functional outcome of bioabsorbable screws in arthroscopic assisted anterior cruciate ligament reconstruction.

\section{Materials and Methodology}

A prospective study was conducted, the data for this study was collected from patients admitted to Rajah Muthiah Medical College and Hospital, Chidambaram, diagnosed to have ACL tear, were treating arthroscopic assisted ACL reconstruction with bioabsorbable interferential screws during the duration June 2015 to June 2017. The clinical and radiological outcome changed into assessed and recorded. The ethical committee clearance was obtained from the group.

\section{Inclusion standards}

1. Isolated ACL tear without or with meniscal injury

2. Age $18-45$ years

3. All cases of acute and chronic ACL tear
4. No previous knee surgical operation

5. Normal contralateral knee

\section{Exclusion criteria}

1. Paediatric ACL injury

2. Infection

3. Osteoarthritic changes in $\mathrm{X}$ ray

\section{Principle}

Bioabsorbable interference screws have in recent times been used instead of stainless steel screws and titanium screws. Bioabsorbable screws go through gradual degradation via organic process and absorbed excreted by body. The hardware associated complications are lesser. Patient compliance more.

\section{Surgical Technique}

Under spinal anaesthesia, under tourniquet control, affected person in supine position, with thigh and foot support. Through midline incision from lower pole of patella to the tibial tuberosity, bone patellar bone graft is harvested, the patella and tibial bone plugs being $2-3 \mathrm{~cm}$ in length, 0.5 $\mathrm{cm}$ depth and $1 \mathrm{~cm}$ in width, the total duration of graft varies from 90 to $100 \mathrm{cms}$. Hoffa's fats pad cleared and ACL remnants eliminated. Notchplasty is executed, $5 \mathrm{~mm}$ of lateral notch is resected, to prevent impingment of the graft and for the visualization of the femoral tunnel entry point. The tibial tunnel access point is made, with the assist of aimer, $3-4 \mathrm{~cm}$ distal and $1.5 \mathrm{~cm}$ medial to the medial joint line. The tibial tunnel is reamed sequentially with cannulated reamers. The tibial tunnel is cleared of debris. Femoral aimer is handed through the tibial tunnel at "over the top" position 10.30 for the right knee and 1.30 for the left knee at the condyle of femur. Beath pin is introduced via the femoral aimer, in order that it comes out through the anterolateral factor of distal end of femur. Sequential reaming of the femoral tunnel done, tunnel is cleared of debris. The bone patella tendon bone graft harvested and organized is now passed via both the tibial and femoral tunnels with the help of beath pin. The BPTB graft is first secured at the femoral end with bioabsorbable interference screw, the graft is tensioned via retaining the knee in $30^{*}$ flexion and 
now the bioabsorbable interferential screw is implemented for tibial tunnel. Wound closed in layers after drain insitu. Patient knee is immobilized with knee brace.

\section{Patellar tendon bone graft harvesting}

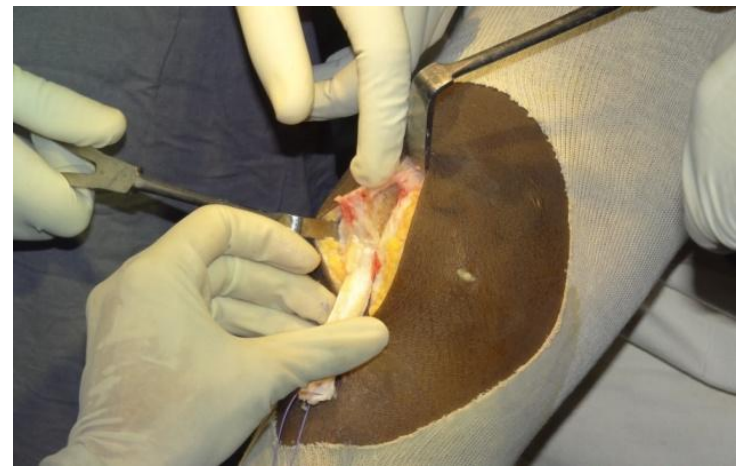

Bio Absorbable Interferential Screw Fixation

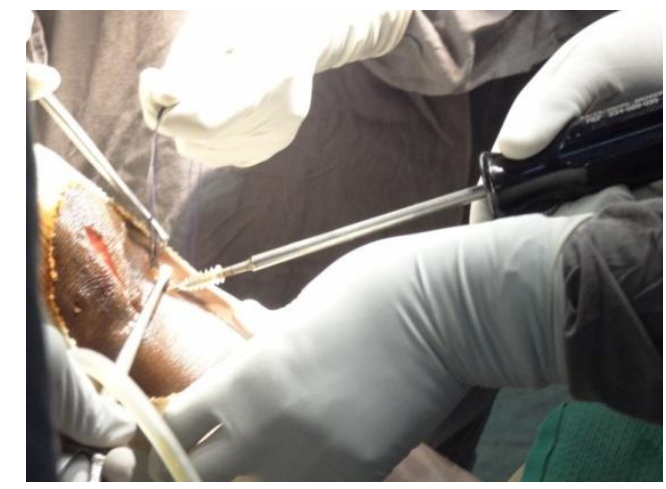

\section{Post Operative rehabilitation}

Compression bandage and long knee brace applied over the operated knee. 4 dose of third generation cephalosporin was given. Rehabilitation was started at the day after surgery underneath the direct supervision of the health care professional. Drain removed at 24-48 hours and drain tip was

\section{Case -1 Pre OP X Ray \& MRi Right Knee}

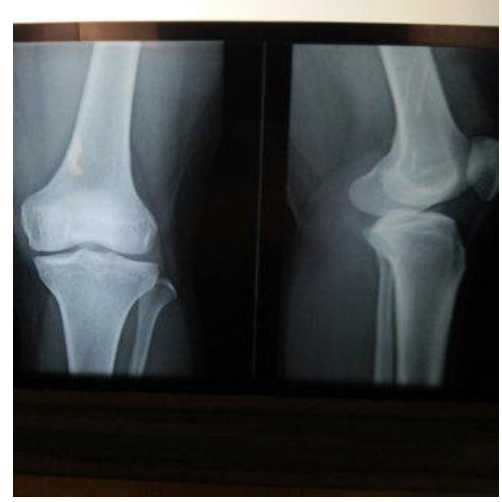

sent for culture and sensitivity as routine. Sutures removed on $12^{\text {th }}$ post operative day. Postoperative $X$ rays had been taken at the operated limb. All patients had been reviewed periodically at 6 weeks, three months, 6 months and 12 months for the evaluation. Functional outcome was determined by using the subjective international knee documentation 2000 scoring system from the immediate post operative duration to the patient returning to the normal daily sports.

\section{Result}

In our study, all observed cases, 27 patient were male $(67.5 \%)$ and 13 were females (32.5\%). The mean age of patients 30.7 years (Range 18- 45 years). Mode of injury RTA- 14 cases, sports activities associated -17 cases, self fall- 9 cases. The time of injury to the day of surgical procedure ranged from 24 to 1 year. The average was 141 days. The operative time ranged from 75 minutes to 90 minutes. All the patients covered for this study underwent ACL reconstruction the usage of BPTB autograft. The graft fixation was done with bioabsorbable interference screws. There become no occurrence of posterior blow out on this series. Results were studied in line with the IKDC scoring system. Anteroposterior translation of reconstructed ligaments changed into assessed through lachmans test. The preoperative IKDC rating $66.42 \%$.The post operative mean IKDC rating is $94.33 \%$. The clincal results are excellent for using bioabsorbable interferential screws for ACL fixation.

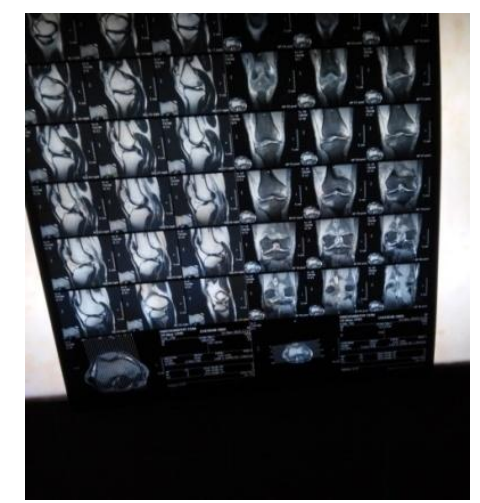




\section{JMSCR Vol||05||Issue||11||Page 30179-30185||November}

Pre Op Picture

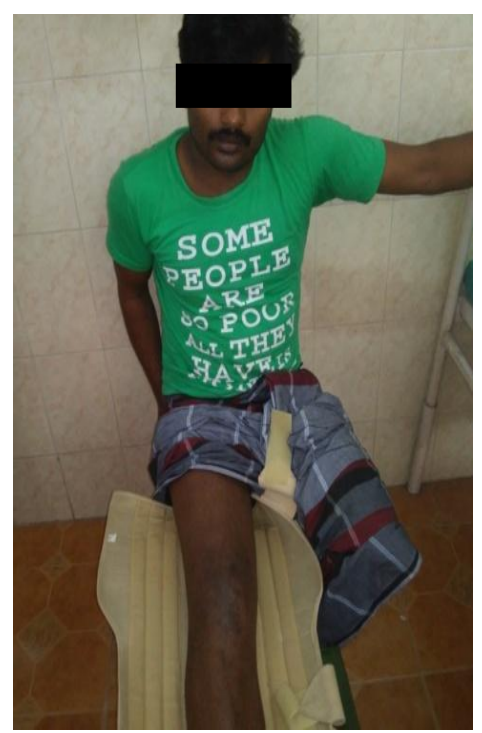

Post Op X-Ray

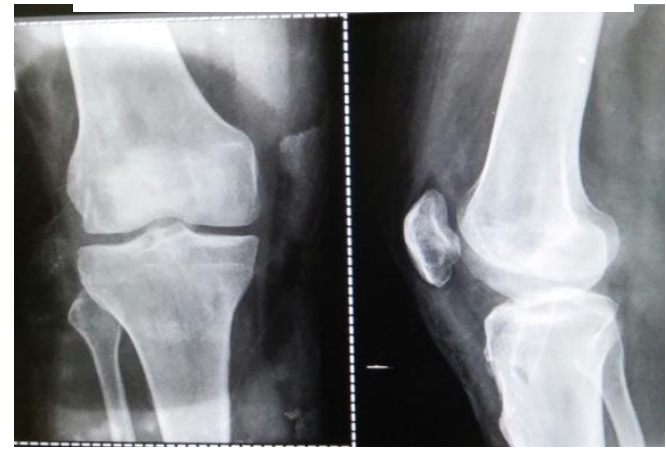

Case- 4 Pre Op X Ray \& MRI Right Knee

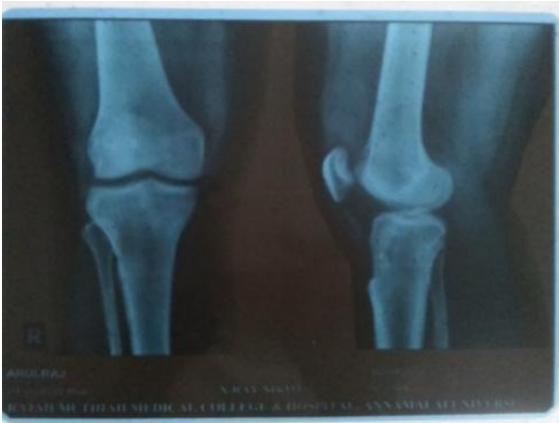

Pre Op Picture

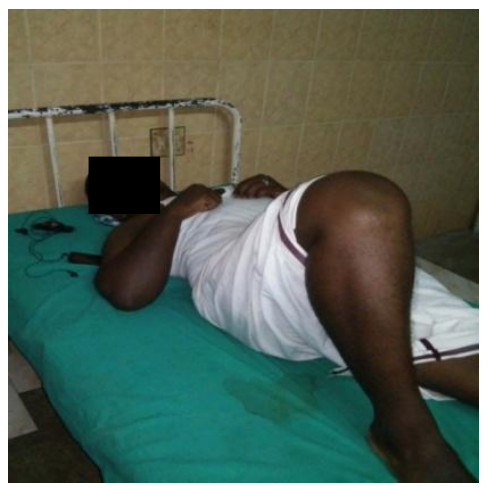

2 Days Post Op Picture

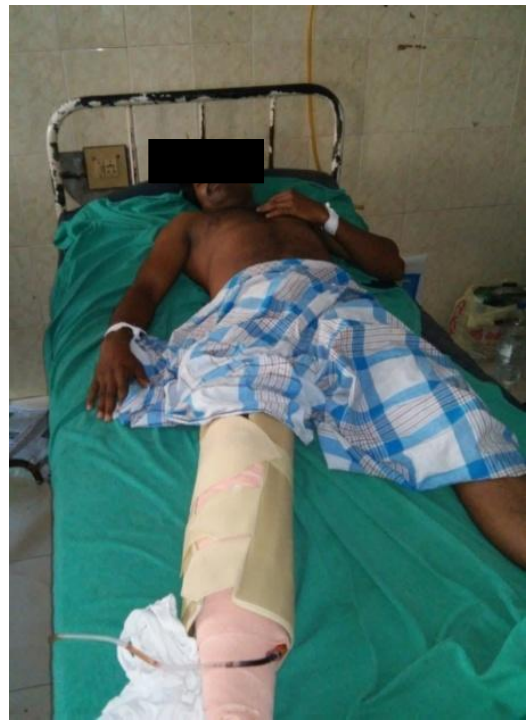

\section{Months Post Op Picture}
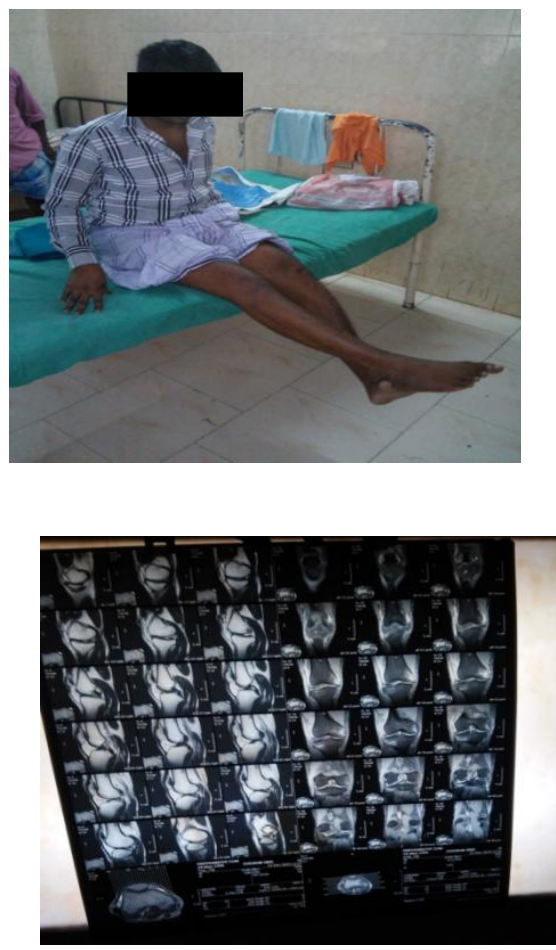

Post Op X-Ray

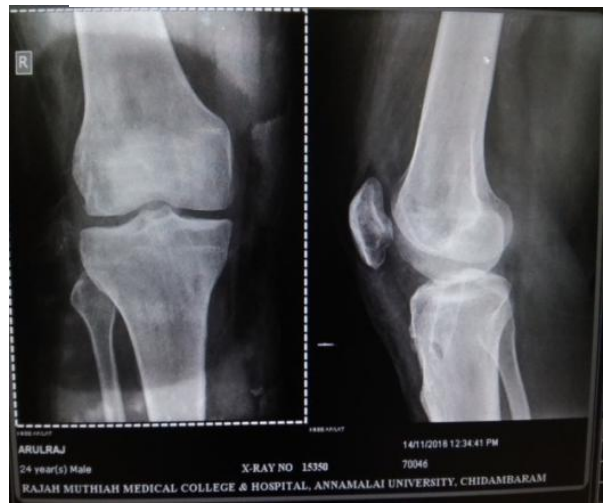


2 Months Post Op Picture

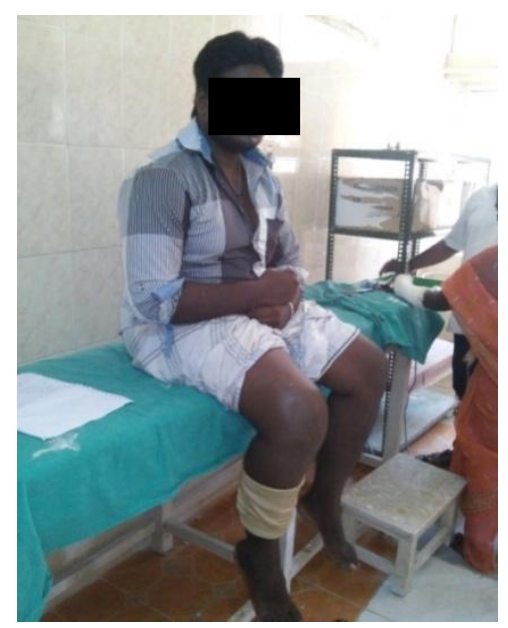

5 Months Post Op Pictures

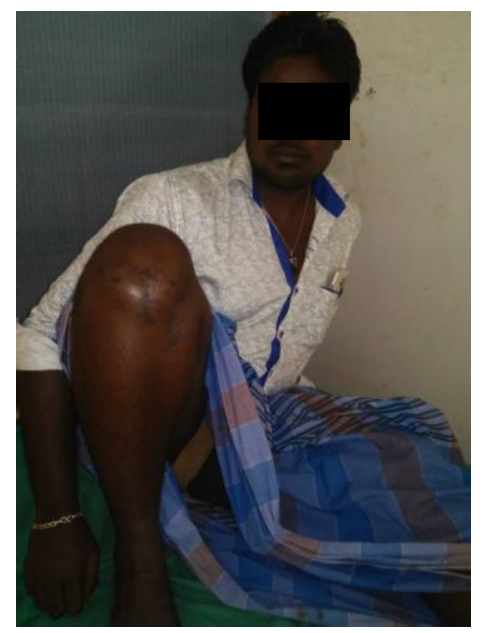

\section{Discussion}

Arthroscopic

ACL reconstruction

with bioabsorbable inferential screws has come to be a common surgical procedure nowadays. A close to normal ligament reconstruction is the intention of any surgeon in so that the functional return will be optimal. Bioabsorbable interference screws are an alternative to metallic implants for ACL reconstruction. The biomaterials used for screw manufacturing range and showcase differing degradation rates. Screws were developed with indications for soft tissue fixation, bone-tendonbone fixation, or both. Screw designs have developed with distinctive traits and technique recommendations to ease insertion, improve fixation, and reduce the occurrence of screw failure during insertion. Various factors play a position in achieving this. Good muscle control, good enough rehabilitation pre operative and post operative, tunnel placement and fixation strength are some factors widely researched. Bioabsorbable screws are product of poly L- lactic acid, poly glycolic acid, hydroxylapatite. Additional materials had been added by using a few producers as an osteoconductive material. The Biocryl screw is a composite of tricalcium phosphate $(30 \%)$ and polylactic acid (70\%).The tricalcium phosphate serves as an osteoconductive material present in the course of the screw ,now not simply the outer surface. Variying the degree of crystallinity has huge have an impact on the degradation charges of these polymers. Highly crystalline screws degrade greater slowly than amorphous substances. Drives spanning the screw length have a lower incidence of screw breakage on insertion .Drive shape impacts the prevalence of screw failure at some point of insertion as well. Tapered screw designs may additionally permit for less complicated screw tunnel engagement. A wide variety of screw sizes are available from each producer. ${ }^{[10]}$

Advantages of bioscrews aren't any need for removal, no metal related complications, radiologically transparent, patient acceptability more. Disadvantages of bioabsorbable screws are choric aseptic synovitis, tunnel widening, intra operative screw breakage, more expensive. In our study we maintaining the following post operative protocals, first begin static quadriceps exercise then after removal of drain slow knee flexion is started, $60 *$ of knee flexion to be completed with the aid of the end of 1 week. If pain permits non weight bearing crutch walking is commenced from day 2. Unaided weight bearing is started out after 6 weeks. Dynamic quadriceps and hamstring physical activities started after 8- 10 weeks.

In our potential examine, we used subjective IKDC scoring system, which confirmed continuously higher scoring in bioabsorbabale screw fixation.

It must be acknowledged that one of the barriers of this study turned into non availability of KT - 
100 scoring, so clinical examination in our study was only subjective. Small size of sample should be stated as some other dilemma. However in regards to the two year follow up of the study, the above cited variables might not particularly impact the functional outcome of the study. Major strength of the present study is that it reports the single centre, similar rehabilitation program.

\section{Conclusion}

40 patients had been taken into the study. All patients underwent ACL reconstruction with bioabsorable interferential screws. The age of the patients ranges from 18 to 45, with a mean average of 30.7. There male preponderance, 27 men as in opposition to 13 women. Commonly right knee affected.

The mode of injury includes sports activities accidents in 17 patents, road traffic accidents in 14 patients and fall 9 patients. The time of injury to the day of surgery ranged from 24 to 365 days. The average was 141 days. The operative time ranged from 75 minutes to 90minutes. As the patients who had associated meniscal tears to cope with took extra operative time, this parameter became now not taken into consideration for evaluation in this study. The graft fixation was done with bioabsorbable interferential screws.

We conclude that our results of arthroscopic assisted ACL reconstruction with bioabsorbable screws in terms of based at the IKDC knee scoring System are excellent arthroscopic reconstruction.

\section{Reference}

1. Garrett WEJ, Swiontkowski MF, Weinstein JN, Callaghan J, Rosier RN, Berry DJ, Harrast J, Derosa GP (2006) American Board of Orthopaedic Surgery Practice of the Orthopaedic Surgeon: PartII, certification examination case mix. J Bone Joint Surg Am 88(3):660-667

2. Gobbi A, Francisco R (2006) Factors affecting return to sports after anterior cruciate ligament reconstruction with patellar tendon and hamstring graft: a prospective clinical investigation. Knee Surg Sports Traumatol Arthrosc 14(10):1021-1028

3. Emond CE, Woelber EB, Kurd SK, Ciccotti MG, Cohen SB (2011) A comparison of the results of anterior cruciate ligament reconstruction using bioabsorbable versus metal interference screws: a meta-analysis. J Bone Joint Surg Am 93(6):572-580

4. Barber FA, Elrod BF, McGuire DA, Paulos LE (1995) Preliminary results of an absorbable interference screw. Arthroscopy 11(5):537-548

5. Halewood C, Hirschmann MT, Newman S, Hleihil J, Chaimski G, Amis AA (2011) the fixation strength of a novel ACL softtissue graft fixation device compared with conventional interference screws: a biomechanical study in vitro. Knee Surg Sports Traumatol Arthrosc 19(4):559-567

6. Drogset JO, Straume LG, Bjorkmo I, Myhr $\mathrm{G}$ (2011) A prospective randomized study of ACL-reconstructions using bonepatellar tendon-bone grafts fixed with bioabsorbable or metal interference screws. Knee Surg Sports Traumatol Arthrosc 19(5):753-759

7. Antunes JC, Oliveira JM, Reis RL, Soria JM, Gomez-Ribelles JL, Mano JF (2010) Novel poly(L-lactic acid)/hyaluronic acid macroporous hybrid scaffolds: characterization and assessment of cytotoxicity. J Biomed Mater Res A 94(3):856-869

8. Piltz S, Strunk P, Meyer L, Plitz W, Lob G (2004) Fixation strength of a novel bioabsorbable expansion bolt for patellar tendon bone graft fixation: an experimental study in calf tibial bone. Knee Surg Sports Traumatol Arthrosc 12(5):376-383

9. Shen C, Jiang SD, Jiang LS, Dai LY (2010) Bioabsorbable versus metallic interference screw fixation in anterior 
cruciate ligament reconstruction: a metaanalysis of randomized controlled trials. Arthroscopy 26(5):705-713

10. Weiler A, Windhagen HG, Raschke MJ, et al: Biodegradable interference screw fixation exhibits pull-out force and stiffness similar to titanium screws. Am J Sports Med 26:119-128, 1998 